\title{
The Philosophical Foundations of Educational Research: a Beginner's Guide
}

\author{
Hussein Assalahi* \\ School of Education, TESOL, University of Exeter, Exeter, UK \\ *Corresponding author: hmaa202@exeter.ac.uk
}

Received January 18, 2015; Revised February 20, 2015; Accepted March 02, 2015

\begin{abstract}
This paper aims to provide a concise introduction about the philosophical underpinnings of educational research. Whilst the philosophies of educational research have been extensively researched, a concise guide is hoped to uncover research underpinnings for beginners' postgraduate research students. It overviews the philosophies, paradigms, basic terminologies and related methodologies of educational research. Moreover, the paper provides insights into how researchers' philosophical stance can inform their research undertaking and transform the educational landscape.
\end{abstract}

Keywords: paradigm, ontology, epistemology, methodology, quantitative, qualitative, mixed-methods

Cite This Article: Hussein Assalahi, “The Philosophical Foundations of Educational Research: a Beginner's Guide.” American Journal of Educational Research, vol. 3, no. 3 (2015): 312-317. doi: 10.12691/education-3-3-10.

\section{Background}

Embracing a new vision is no easy undertaking. The same holds true for a novice researcher gearing up to take on anew identity which is challenging enough to be pursued within specific time constraints and stressful submission deadlines. As a doctorate freshman, I exactly remember how perplexed and disappointed I was when I indulged into extensive reading about educational research. The reason for my bewilderment was due to, I believe, the endless yet painstaking reading lists that I had to go through to make myself professionally aware of all that 'philosophies of educational research' implies. Insofar as the reading task was long enough to be discouraging, the jargons and terminologies of educational research were twice as much annoying. This grievance was to a certain extent due to the 'conflict' that has emerged from the evolution of educational research or as widely recognized in the literature as the 'paradigms war' (Gage, 1989). I was desperate to see a 'survival toolkit' that would suffice the purpose of at least grasping a true picture of the educational research enterprise by a novice reader and researcher.

I think that the hassle for a novice reader stems from the lack of expertise to trace the evolution of what has come to be known as research paradigms. In particular, beginner researchers' focus might dwell more on the fundamentally philosophical question 'what is the paradigmatic stance of the researcher when conducting research?' It could be said that this question might have been sparked after research in social sciences has undergone dramatic theoretical changes since it has come to being. The domain of theoretical framework diversity duly inspired "paradigm shifts" which "involve replacing one way of thinking about knowledge and research with another incommensurable view" (Donmoyer, 2006, p. 11). Such a change, in turn, influences the methodology or design of research. This evolution that research reference books detail is not straightforwardly disseminated to be understood by novice researchers.

Writing this article, therefore, has come as a response to my frustration to understand the basics of research philosophy stimulated by the daunting tasks of reading repeatedly and persistently from huge pile of academic research. The aim of this paper is to provide brief introduction and description of the main constructs of research to beginners in the journey of educational research. I will examine three major research paradigms which have dominated the bulk of educational research since the middle of the eighteenth century, namely, the positivist, interpretive and critical theories. I will shed some light on the history and evolution of eachparadigmin terms of ontology, epistemology and methodology.

\section{Educational Research and Paradigms}

Just as there are several assumptions or 'views of thinking' about research, there are various underlying definitions of research as well. Research is "a systematic method of gaining new information, or a way to answer questions" (Gliner\& Morgan. 2000, p. 4). Others such as Cohen et al (2000), Mackenzie and Knipe (2006), and Midraj et al (2007) define research as a systematic and controlled enquiry through which data are collected, analysed and interpreted to eliminate difficulties and improve conditions. This systematic orientation has generated a number of research methodologies under the umbrella of different paradigms. Hence, a research paradigm is "a cluster of beliefs and dictates which for scientists in a particular discipline influence what should be studied, how research should be done, how results should be interpreted, and so on" (Bryman, 1992, p. 4). Therefore, a 'paradigm' implies the philosophical positions of researchers about the nature of matter, what can be known and how this knowledge can be attained 
(Clark, 1998). More precisely, Naghton et al in Mackenzie and Knipe (2006)identified three components of a paradigm; a belief about the nature of knowledge, a methodology and criteria for validity. So, three terminologies demonstrate the foundational constructs of research paradigm and these will be discussed below.

\subsection{Ontology, Epistemology and Methodology}

A philosophical belief or 'paradigmatic stance' would prompt researchers' thinking about the 'entity' of phenomena or the ontology. This term refers to the study of being and the nature of the reality (Crotty, 1998; Cohen et al, 2000). The second element that researchers should be made aware of is epistemology which concerns "the views about the ways in which social reality ought to be studied" (Bryman, 1992, p. 5). Specifically, epistemology focuses on the origins and nature of knowing, the construction of knowledge and the relationship between the knower and the known (Maykut \& Morehouse, 1994).

The third construct of a paradigm, methodology, refers to the study of the epistemological assumptions implicit in specific method which encompass our entire approach to research, our assumptions about nature of knowledge and the methods of data collection and analysis (DeMarrais\& Lapan, 2004).

To sum up, a paradigm consists of at least three elements; ontology, epistemology and methodology. However, every construct of each paradigm has different connotations depending on the underpinning theoretical framework. These issues will be discussed in relation to three major research theories; the positivist, interpretive and critical paradigms.

\subsubsection{Positivistic Paradigm}

Positivism is a stretched terminology of the 'positive' science and 'positive' philosophy which appeared in Francis Bacon's writings in the 16th century (Crotty, 1998). However, Auguste Comte (1830s) is considered its founder and populariser. Ever since, positivism which dominated the bulk of social research until the 1960s has emerged as a reaction to metaphysics and theology (Carr \& Kemmis, 1986; Cohen et al, 2000). It is based on universality of laws and emphasizes the existence of "common reality on which people can agree" (Newman \& Benz, 1998, p. 2). Positivism contends that these realities are meaningful as long as they are observable, replicable and verifiable(Anderson, 1998). Moreover, the methods and procedures applicable in natural sciences can be utilized in social sciences. Comparatively, positivism accepts a posited direct experience and verifiable knowledge, but rejects whatever abstract, subjective or metaphysical (Crotty, 1998). Logical positivists "give meaning to statements by methods of its verification", and that researchers observe human behaviouras external, repetitive and predictable by forming hypothesis, and applying scientific methods to form law-like generalizations (Cohen et al, 2000, p. 8).

The ontological assumptions underpinning positivism pertain to the existence of independent realities outside the mind (Crotty, 1998). Objectivism is the term generally used to describe the ontological stance of positivism. To call anything 'real' means it is out there detached from the individuals. Positivists claim that researchers in social sciences should consider concepts as objective and 'real' so that they can be deemed verifiable (Cohen et al, 2000).

Realism, the epistemological assumption of positivism, holds that meanings reside within entities as objective truth and independent of the human mind (Crotty, 1998). That being said, it is implied that researchers should strive to detach themselves from the reality under investigation and distance themselves from those studied in order to prevent or minimize researcher's bias. They need to "bracket out their value systems and discover what is, and their accounts as a result correspond with that reality in a straight-forward way" (Scott\& Usher, 2011, p. 147). Therefore, positivists claim that the researcher seeks to explain the reality by means of objective observation, verification and measurement (Anderson, 1998; Midraj et al, 2007; Clark, 1998).

In summary, positivists emphasise objectivity when discovering reality. This stance informs methodologies as part of the overall design in the process of inquiry.

Empirically speaking, quantitative research aims at theory testing. This can be accomplished by reviewing previous research and established theories, and then postulating a hypothesis which informs congruent data collection method(s) and analysis to check whether findings confirm or contradict that theory. Howe (1988) draws a clear description of the quantitative researcher's position in designing his/her study as follows:

"The quantitative researcher (rightly or wrongly) is willing to assume much, i.e., that all confounding variables have been identified and that the variables of interest have validly measured; qualitative researchers are also much less interested in actors points of view" $P$. 12.

Positivists begin their research process by formulating hypotheses which are tentative suppositions derived from previous theories (Carr \& Kemmis, 1986). Central to the hypothesis are the concepts or variables that should have operational definitions to render them measurable (Bryman, 1992). Literally, hypotheses should precede data collection (Midraj et al, 2007).

\subsubsection{Methodology}

Empiricism is the terminology that represents the quantitative methodological approaches and designs in social sciences. Positivists assume that they can produce scientific explanations of the occurrence of events by implementing quantitative approaches or methods of data collection and analysis through experiment and observation or causality principles (Carr \& Kemmis, 1986; Mackenzie \& Knipe, 2006). Newman and Benz (1998)reported that quantitative designs include:

"Experimental studies, quasi-experimental studies, pretest-postest designs, and others (Campbell \& Stanley, 1963), where control of variables, randomization, valid and reliable measures are required and where generalizability from the sample to the population is the aim. Data in quantitative studies are coded according to a priori operational and standardized definitions" (P. 10). [Italics added].

The tenets of positivism then emphasize the fact that knowledge is observable and therefore measurable in ways identical or, to a lesser extent, similar to pure scientific experiments, i.e. truth can be verified via scientific or quasi-scientific methods. To this end, 
positivist researchers should be aware of distinctions between methodological designs and methods to be used. Quantitative methodologies define the approach which inform data collection methods and analyses. The next section will discern two of the most widely used research methodologies in quantitative research; survey and experimental designs (Bryman, 1992; Wallen \& Fraenkle, 2001; Denscombe, 2007).

\subsubsection{Surveys Designs}

In line with the worldview of positivism, survey design entail empiricist verification of theoretical positions by studying a "phenomenon comprehensively and in detail" (Denscombe, 2007, p. 7). Under survey, quantitative methodologies represent terms such as correlational, cross-sectional, and explanatory research. In this regards, data collection from samples of large populations can be attained by using questionnaires which are basically batteries of questions that measure the main variables (dependent and independent) to determine whether correlations exist or not. Other methods include observation and structured interviews which also try to explain human behaviour and predict likely outcomes.

\subsubsection{Quasi-Experimental Designs}

Another postulation of positivism, which is rooted in the extreme view of pure sciences, is to provide rational explanation of the occurrence of phenomena which can be achieved by means of experimentation. Under this category, experimental or quasi-experimental designs could be used as the underlying methodologies (Scott \& Usher, 2011). To comply with objectivity, researchers should pay close attention to issues such as assigning two research groups randomly; one is experimental that undergoes stimulus or independent variable whereas the other is the control group that remain intact and do not undergo experimentation. This way, it is assumed that human behaviour would be objectively investigated via causation, causality and outcomes could successfully be predicted, explained and generalized.

The emphasis of positivism on objectivity and measurability in research is due to its obsession with generalizations. Positivist researchers generalize internally; within the sample, and externally; across other contexts. This can be achieved through random sampling of large populations and careful consideration of validity and reliability issues (Midraj et al, 2007). A measure is said to be valid if it "measures what it purports to measure" (Cohen et al, 2000, p. 105). Issues such as "careful sampling, appropriate instrumentation and appropriate statistical treatments of the data" reflect the validity of quantitative research. Reliability, on the other hand, refers to the "consistency of a measure" (Bryman, 1992, p. 29). There are two types of consistency; internal and time consistency. The former relates to the coherence of a scale. The latter is concerned with measure's consistency over time; applied more than one time. A third significant party to reliability and validity is triangulation which is the "use of two or more methods of data collection in the study of some aspect of human behaviour" (Cohen et al, 2000, p. 112). So, the more data collection methods there are, the more valid and reliable the research will be

\subsubsection{Criticisms of Positivism}

Positivism has been considered as the foundation on which social sciences were distinguished against the dominant metaphysical grip. Issues such as precession, clarity and scientific thinking were substantially introduced to explain the occurrence of a phenomenon. However, a number of critiques can be levelled against positivism. First, as far as ontology is concerned, it goes without saying that entities exist outside the mind, but conceptually they are inseparable parts of our consciousness because we attach meaning to them as well. In addition, it is impossible to reach agreement and cast generalisations over a social behaviour as humans have different perceptions. Therefore, reality is an ambiguous and contradictory tenet of positivism, especially in the realm of social sciences. Second, the paradoxical tenets of positivism get more intense when it comes to epistemology. The detachment of the researcher from the truth or the 'value free' observation is conceivable in natural but not social sciences. This assumption turns a blind eye on humanistic dimensions of research participants. Positivistic researchers tend to visualise research participants as simply 'objects' whose roles are restricted to elicitation of information or participating in quasi-experimental designs. In this regard, positivism appears to be oblivious to the creativeness of human beings by objectifying their actions into observable and generalizable behaviours. Moreover, positivism cannot stand for the differences between individuals with regards to meaning making. For example, teachers and students have different perceptions about a learning or teaching concept. Consequently, their behaviours cannot be governed because of different conceptualizations. Positivists' obsession with generalization is untenable since different phenomenon have different meanings in different contexts. Thus, depression may denote suicide in one context, but may simply mean a matter of having a glass of wine in other situations, or a need for empowerment through spiritual, ritual and religious practices. Finally, a serious assumption about positivism is that by means of precision it implies the establishment of generalizable certainties and 'objective truths' (Crotty, 1998).

To conclude, whilst positivism has served social sciences research, claiming and generalizing objective truths have been strongly challenged. Additionally, reducing the essence of human beings to a set of controlled, predictable and governed behaviours is not tenable and conceivable in social sciences. Such criticisms gave rise to the interpretivist theory which will be introduced next.

\subsection{Interpretive Paradigm}

Interpretivism has come to light after the withering criticisms that have been levelled at positivism in the 1960s (Carr\&Kemmis, 1986); mainly its ignorance of the social factors that distinguish human beings. The founder of interpretivism, Max Weber, a German sociologist, greatly influenced the social theory by refuting positivism and substituting scientific with social philosophies (interpretive) in meaning construction (Crotty, 1998). Unlike positivists, interpretivists are concerned with "understanding the subjective world of the human experience" (Cohen et al, 2000, p. 22). Human behaviours 
cannot be explained by merely implementing methods of natural sciences. Rather, as part of our consciousness and due to our interaction with the world in which we live, behaviours can be understood by researchers only via those who perform them and the context in which they occur. Thus, interpretivist researchers concentrate on qualitative rather than quantitative aspects or relationships (Wallen \& Fraenkel, 2001).

Subjectivism(or relativism) as the ontological stance of interpretivism views reality as multiple and relative. For interpretivists, reality is "a social construct, multiple that embraces multiple interpretations"(Newman \& Benz, 1998, p. 2). Reality is part of the mind even if entities are external because they are created and given meaning through our perceptions. Crotty (1998) indicates that "the term human being means being in the world" (P. 45).

As far as epistemology is concerned, Constructionism (and social constructionism) is the term that generally represents interpretivists' philosophical stance. Interpretivsts believe that knowledge is constructed via the participants. That is to say, participants are considered active knowers who understand and reflect on the social phenomena. Researchers can mutually attain an understanding of the phenomenon under investigation by interpreting the intentions of those involved (Cohen et al, 2000). Additionally, researchers work as part of rather than detached from the research where "knowledge is jointly constructed between researchers and their collaborators" (Dunne et al, 2005, p. 15).

\subsubsection{Design}

Qualitative research aims to understand and uncover what is going on in a social context. Hence, it is concerned with "observing and interpreting reality with the aim of developing a theory that will explain what was experienced" (Newman \& Benz, 1998, p. 3). The essence of research depends on the situation being studied. Therefore, the research has no specific structure (Howe, 1988). Rather, it may change over time according to the emergent phenomena.

\subsubsection{Methodology}

There are different types of qualitative methodologies and research designs. However, there are common features of the interpretive methodological designs which can be distinguished from other research designs (Wallen \& Fraenkle, 2001):

1. Qualitative researchers are interested in exploring and describing the contextualized social reality through the eyes of the participants.

2. Deeper understanding, by means of collecting and categorizing, of data and actions of participants is sought rather than generalizing.

3. Through observation of purposive sample, we can choose the suitable questions and design.

4. Detailed descriptions of the results of underlying patterns of the collected data should entail the study.

5. Although generalization is not the aim, validity (trustworthiness) and reliability (dependability) should be established so that the reader is convinced of the findings of the study.

So, there are a number of interpretive methodologies that are worth exploring. However, I will shed some light on the common interpretive approaches in educational research.

\subsubsection{Ethnography}

Ethnography literally means "descriptions of people or cultures" (Descombe, 2003, p. 84). From an epistemological point of view, it is crucial for ethnographers to understand the social behaviour from the perspectives of research participants (Fattermanl, 2008). As a research methodology, ethnography gives the researcher the chance to gain deeper insights of the lives of the studied groups or individuals in order to, as Malinowski (1922) in Denscombe (2007) put it, " realize [their] vision of [their] world" (P. 62). However, it should be recognized that this realization should be "holistic" by relating it to the sociocultural context in which it exists. The findings represent the researcher's interpretation of informants' perceptions and their experiences of the phenomenon under investigation. Excerpts of the participant's discourse and their analysis should be provided. In general, gaining deeper insights about the phenomenon is usually emphasized over how representative the sample is.

\subsubsection{Phenomenology}

The term phenomenology was developed by Hussler (1970) and refers to the raw knowledge we have about a situation, an idea or experience. It also means "describing things as one experiences them" (O'Donoghue\& Punch, 2003, p. 45). it is concerned with daily situations or events that are usually regarded trivial and mundane, but only according to the understandings of those involved can we portray their interpretations faithfully to turn what might have been trivial into something meaningful. As such, phenomenology considers in multiple realities that can be understood, interpreted and constructed through communicating directly with those participants and others within the society to gain deeper insights into their lived experiences about the phenomena under study. Another difference relies in phenomenology's focus on how the events get interpreted by others rather than on only describing what is going on in a situation (Denscombe, 2007).

\subsubsection{Case Study}

It is one of the common research designs used by interpretivists in small scale studies which focus on individual cases, in their natural course of action, to be studied in depth and detail (Denscombe, 2007). It aims at uncovering the reasons behind the occurrence of a thing and discerning the interrelated factors. Quite significantly, case studies allow the use of more than one data collection method such as documents, interviews, and questionnaires (Anderson, 1998; Denscombe, 2007).

The essential task for interpretivist researchers is to convince their readers about the extent to which their research make up a robust inquiry. In other words, researchers in qualitative research should demonstrate the "goodness" or "soundness", "trustworthiness" and "credibility" of their research study (Miller, 2008, p. 909). This can be sustained throughout the research by taking into consideration issues such as representative excerpts of analysed data, sufficient sampling, self-reflection, theoretical thinking, peer-review and member check (ibid). 


\subsubsection{Criticisms of the Interpretive Paradigm}

Interpretivism has gained momentum in social sciences since it foregrounds researchers' subjectivity in the phenomenon. However, several shortcomings can be pointed out. First, there are chances for high partiality levels of the researcher since his role is more subjective. Second, once the researcher is involved in a research undertaking, it is no more natural as posited by interpretivists. Therefore, researchers may inevitably influence the whole intervention. On the other hand, by relying on participants' single accounts researchers might find it difficult to sustain trustworthiness and dependability of the research inquiry. Third, it does not find currency in pragmatic situations where solutions to social issues and generalisations are desired. Hence, it is perceived as only theoretical not practical. These criticisms gave rise to the practical and political or emancipatory oriented paradigm, which will follow.

\section{Critical Theory}

Critical theory came contrary to, and goes beyond positivistic and interpretive theories where their focus is on technical and hermeneutic knowledge respectively (Carr \& Kemmis, 1986; crotty, 1998; Cohen et al, 2000). For the critical theory, status change and 'ideology critique' are among its paramount goals. In other words, "understanding and challenging the workings of ideology has been a dominant concern, one often expressed as 'ideology critique" (Brookfield, 2005, p. 42). One of its great contributions is bridging the gap between theory and practice in educational research. That is to say, critical theorists posit that objectivity in positivism does not say much about the educational problems because it prescribes generalized solutions. Interpretivism, on the other hand, is not "in itself sufficient" because the knowledge that it justifies might sustain some form of false beliefs and thus sets to transform consciousness not practice (Ingram \& Simon-Ingram, 1992). So, it is the responsibility of the critical theory to emancipate people from such repressive and taken for granted ideas (Carr \& Kemmis, 1986, p. 129). Its principal intentions are two fold; political and transformative. The former is concerned with emancipating and empowering educationalists; emancipation from the power agendas imposed on them. Hence, critical theory depicts those imposed interests and questions their legitimacy with regards to equality and democratic orientations (Carr \& Kemmis). On the other hand, critical theory is transformative in the sense that it' seeks to "transform the society and individuals to social democracy" (Cohen et al, 2000, p. 28).

Ontologically speaking, the reality represented by critical theory is not easily identified. Jones (2001) contends that "critical theory is not characterized by a commitment to a particular epistemology or to a specific ontology" (P. 9). However, a crucial characteristic of reality can be elucidated as part of our interests (Ingram\& Simon-Ingram, 1992). A more important feature of critical reality is that it simultaneously recognizes the existence of knowledge independent of humans but also acknowledges the socially embedded and fallible nature of scientific inquiry(Clark, 2010).
With regards to epistemology, Habermasstated that knowledge has three components: "prediction and control, understanding and interpretation, emancipation and freedom" (Cohen et al, 2000, 29).From this perspective, knowledge in critical theory subsumes positivism, as regards natural objects, meanwhile include sinterpretivism, as regards communication, and aims further to unpack hidden interests. However, the researcher's role is participatory, socially and politically oriented (Cohen et al, 2000; Kemmis, 1986).

\subsection{Methodology}

Critical research project begins with a study of culture using hermeneutic reconstructive methodology (Phil, 2008). Critical theorists, then, may merge the positivistic "rigorous, causal explanation" features with the interpretivist hermeneutic methods into a more practical and "self-reflective" action that helps individuals determine, explain and eliminate historical causes of their frustration (Carr \& Kemmis, 1986, p. 136). Critical theory, then, should come up with a method which "attempts to distil the historical processes which have caused subjective meanings to become systematically distorted" (ibid).In this regard, action research is widely recognized as a methodological design which demonstrate tenets of critical theory.

Action research is "a form of self-reflective enquiry undertaken by participants in social situations in order to improve the rationality and justice for their own practices, their understanding of these practices, and the situations in which the practices are carried out" (Carr \& Kemmis, 1986, p. 162).According to Cohen et al (2000) and Somekh (2008), Kurt Lewin is recognised as the founder of action research. In order to have their voices heard and their problems solved, teachers, individuals, groups and the like should undertake action research. However, it is mainly collaborative, systematic and reflective. Additionally, it is commenced by those who feel suppressed so that they can uncover their repressed identities and the hidden powers that cause their subjugation.

Having introduced action research in critical theory, there is no such prototype for action research methodology. However, action research uses "eclectic methodologies" with case study being the most dominant (Cohen et al, 2000, p. 228). This diversity of methodologies stems from the fact that action research utilised qualitative methodologies by dying it with scientific rationality of the quantitative methodology in order determine the causes and eliminate problems through systematic dialogue or discourse. By and large, action research should start by identifying a problem, planning solutions, then implementing and evaluating such solutions to in an attempt to emancipate participants.

Finally, issues of validity and reliability in action research are of high importance. Validity in action research refers to the pragmatic nature of research; how applicable and emancipatory the research is. So, a valid research is one that portrays the ideas of the oppressed to be empowered. Phill (2008) best describes indicators of validity in educational research as the participants' recognition of their own and the researcher's interpretation of the implicit cultural milieu. In this case, reliability issues in critical theory, then, echo those of the interpretive paradigm. 


\subsection{Criticisms of Critical Theory}

Despite the emancipatory interests of the critical theory, it is not immune to criticism. First, critical theory needs more clarification since its aims are ambiguous. It strives to achieve its emancipatory agendas in principal. But, how? This is still ambiguous in so far as a number of forms and approaches of critical theory exist (Carr \& Kemmis, 1986). Another critique concerns the interwoven knowledge that encompasses the positivistic, interpretive and emancipatory aims. This entanglement makes it difficult to attain the knowledge and then eliminate all obstacles of social justice. Finally, as Cohen et al (2000) posits, selfreflectiveness or critique is not a prerequisite for emancipation especially in educational settings.

\section{Conclusion: Which Paradigm?}

Having broadly and concisely introduced the positivist, interpretivist and critical paradigms and their implementation in social sciences research, the question to be raised, in the eyes of novice researchers and to scholars to a certain extent as well, is which philosophical assumptions to follow in conducting research?

To start with, there is no clear-cut answer to this question but it suffices to say that agency to one's belief system would probably guide decision-making (Guba\& Lincoln, 1994). Yet, researchers' debates over the divergence or convergence of methodologies in research generated a robust approach known as the mixed-methodology research design. This research design integrates both quantitative and qualitative methods of inquiry to be conducive to the richness and quality of evidence (Patton, 1990). The mixedmethodology approach is based on pragmatism which allows for the integration of methods into a single research study (Creswell, 1994; Brannen, 2009).

My personal beliefs about the issue of paradigms' dilemmas are more aligned with the tenets of pragmatism in relation to mixed-methods research. Within this paradigm, researchers can investigate the phenomenon under study form different angles to gain both depth and breadth of reality. Although I believe that the philosophical underpinnings of positivistic and interpretive paradigms are distinctive and self-contained, gaining robust and rigorous findings appeal to me more than philosophical conflicts. Brannen (2009) notes that “.....recent years have seen a growth in research which serves strategic goals and a move away from theoretically driven research ...” (p. 9).

Finally, Brannen's contention that research value depends more on pragmatic measures rather than theoretical triumph struck a note. Novice researchers who are confused by the so-called "paradigm wars" might find pragmatism easier to embrace if they would like to just 'get along with it' (Onwuegbuzie, 2002).

\section{References}

[1] Anderson, Gary, and Gary J. Anderson. Fundamentals of educational research. Psychology Press, 1998.

[2] Brannen, J. Mixed methods for novice researches: Reflections and themes. International Journal of Multiple Research Approaches, 2009, 3, 8-12.

[3] Brookfield, S. D. The power of critical theory for adult learning and teaching. Maidenhead: Open University Press. 2005.
[4] Bryman, A. Quantity and quality in social research. London: Routledge. 1992.

[5] Carr, W., \&Kemmis, S. Becoming critical: Education, knowledge and action research. London: Falmer Press. 1986.

[6] Clark, A. M. "Critical realism." In The Sage Encyclopedia of Qualitative Research Methods. Sage Publications. Retrieved January, 8, 2010, from http://0-sageereference.com.lib.exeter.ac.uk/research/Article_n87.html

[7] Clark, A. M. The qualitative-quantitative debate: Moving from positivism and confrontation to post-positivism and reconciliation. Journal of Advanced Nursing, 1998, 27, 1242-1249.

[8] Cohen, L., Manion, L., \& Morrison, K. Research methods in education. (5th Ed). London: Falmer Press. 2000.

[9] Creswell, J. W. Research design: Qualitative and quantitative approaches. Thousand Oaks, Calif.: Sage Publications. 1994

[10] Crotty, M..The foundations of social research: meaning and perspective in the research process. London: Sage Publications. 1998

[11] DeMarrais, K. B., \&Lapan, S. D. Foundations for research methods of inquiry in education and the social sciences. Mahwah, N.J.: L. Erlbaum Associates. 2004.

[12] Denscombe, M. The good research guide for small scale social research projects. Maidenhead, England: Open University Press. 2007.

[13] Donmoyer, R. Take my paradigm ...please! The legacy of Kuhn's construct in educational research. International Journal of qualitative studies in Education, 2006, 19, 1, 11-34.

[14] Dunne, M., Pryor, J., \& Yates, P.Becoming a researcher: A companion to the research process. Maidenhead, England: Open University Press. 2005.

[15] Gage, N. L. (1989). The paradigm wars and their aftermath a "historical" sketch of research on teaching since 1989. Educational researcher, 18 (7), 4-10.

[16] Howe, K. R. Against The quantitative-qualitative incompatibility Thesis or dogmas die hard. Educational Researcher, 1989, 17, 8, 10-16.

[17] Ingram, D., \& Simon-Ingram, J. Critical theory: The essential readings. New York: Paragon House. 1992

[18] Jeffrey A. G., \& George A. M. Research methods in applied settings: An integrated approach to design and analysis. Mahwah: Lawrence Erlbaum Associates Inc. 2000).

[19] Jones, R. W. Critical theory and world politics. London: Lynne Rienner. 2001.

[20] Mackenzie, N. \&Knipe, S. Research dilemmas: Paradigms, methods and methodology, Issues in Educational Research, 16, 2, 193-205. Retrieved January, 27, 2010, from http://www.iier.org.au/iier16/mackenzie.html,

[21] Maykut:,\& Morehouse, R. Beginning qualitative research: A philosophic and practical guide. London: Falmer Press. 1994.

[22] Midraj, S. Jendli, A and Sellami, A. (Eds) Research in ELT contexts. Dubai: Tesol Arabia Publications. 2007

[23] Miller, P. (2008). Validity. In Given, L. M. The Sage Encyclopedia of Qualitative Research Methods. Los Angeles, Calif: Sage Publications. Retrieved January, 8, 2010, from http://0-sageereference.com.lib.exeter.ac.uk/research/Article_n477.hml

[24] Newman, I., \& Benz, C. R. Qualitative-quantitative research methodology: Exploring the interactive continuum. Carbondale, IL: Southern Illinois University Press. 1998.

[25] O'Donoghue, T. \& Punch, K. Qualitative educational research in action: Doing and reflecting. London: Routledge Falmer. 2003.

[26] Onwuegbuzie, A. J. Positivists, post-positivists, post-structuralists, and post-modernists: Why can't we all get along? Towards a framework for unifying research paradigms. Education, 2002, 122, 518-530.

[27] Phill, F. C. "Critical Research." In The Sage Encyclopedia of Qualitative Research Methods. Sage Publications. Retrieved January, 8, 2010, from http://0-sageereference.com.lib.exeter.ac.uk/research/Article_n88.html

[28] Scott, D., \& Usher, R. Researching education: data, methods and theory in educational enquiry. (2011) Bloomsbury Publishing.

[29] Somekh, B. "Action research." In The Sage Encyclopedia of Qualitative Research Methods. Sage Publications. Retrieved January, 28, 2010, from http://0-sageereference.com.lib.exeter.ac.uk/research/Article_n4.html.

[30] Wallen, N. E. \&Fraenkel, J. R. Educational research: A guide to the process (2nd ed.). New York: Lawrence Erlbaum Associates. 2001 